\title{
ENHANCING STUDENTS' LEARNING EXPERIENCES AND RECOURSES THROUGH THE ADOPTION OF E-EXAMS AT CQ UNIVERSITY
}

\author{
Santoso Wibowo, Srimannarayana Grandhi, Ritesh Chugh \\ Central Queensland University, Melbourne, Australia \\ Corresponding email: s.wibowo1@cqu.edu.au
}

\begin{abstract}
This study sought students' views about e-exams at CQUniversity with its multiple campus locations. Data were gathered by conducting four focus group interviews with students enrolled at three different courses. After completing the e-exams consisting of short-answers and essaytype questions, the students participated in a focus group interviews. They were asked their views of the current e-exams software, the benefits and challenges and the prospects of e-exams. The students reported the ineffectiveness of the software particularly with the navigation system, which lacked useful features. In general, the students were positive about the adoption of e-exam and suggested a number of improvements in the software and in the management of e-exams. Findings from this small-scale study could be used as a point of reference for future adoption of e-exams at CQUniversity.
\end{abstract}

Keywords: Electronic Exams, Higher Education, Pedagogical Development, Information Communication and Technology, Mock-exams, E-Exam Software.

\section{Introduction}

Many higher education institutions nowadays have shifted their examination procedures from paper-based to IT-based exams also known as e-exams. The potentials of e-exams have been widely cited in the literature. An examination conducted electronically reduce teachers' workload on examination from preparation and process of a larger amount of examinations to final grading (Lyell \& McNamara, 2000; Shermis, et al., 2001) avoid cheating by the students (Adegbija, Fakomogbon \& Daramola, 2012) and promoted effective learning by testing a range of skills, knowledge and understanding (Bodmann \& Robinson, 2004; Jamila \& Shami, 2012). E-exams have been very effective in providing immediate feedback to a larger number of students participating in exams (Lyell \& McNamara, 2000; Shermis, et al, 2001; Jamila \& Shami, 2012). E-exams are particularly relevant for distance education as they accelerate the whole process of examination (Thomas et al, 2002). There are however, challenges that come along with the adoption of e-exams. Some teachers are still reluctant to adopt e-exams as they are inclined to change their examination habits (Kuikka, Kitola \& Laakso, 2014; Joseph, 2012). A number of factors such as security, human interference, the complexity of the software and inadequate training for staff and students constitute a major challenge on the implementation of e-exams (Adebayo \& Abdulhamid, 2010; Adegbija, Fakomogbon \& Daramola, 2012). Students, who are not familiar and confident with e-exams, find the system challenging (Thomas et al, 2002). 
Despite the potentials of e-exams, paper-based exams are still commonly used as a means of assessment by higher education institutions (Osang, 2012; Hiller, 2014). The University of Queensland and the University of Tasmania are among the few universities in Australia adopting e-exams (Hiller \& Fluck, 2013). The University of Tasmania has successfully adopted e-exams in all courses across the university (University of Tasmania, 2014). CQUniversity as one of the most dynamic Australian universities has just started implementing e-exams in its geographically dispersed campuses. The aims of the study are to (a) understand currently available e-exam systems, (b) to explore challenges and opportunities associated with the existing e-exams system and (c) to develop best practices for the successful implementation of eexams across CQUniversity.

\section{Methodology}

Keep line spacing at 1. Font type is Georgia. Font size is 11pt. Please do not alter the formatting and style layouts which have been set up in this template document. Do not indent the first paragraph in each section. Keep line spacing at 1. Font type is Georgia. Font size is 11pt. Please do not alter the formatting and style layouts which have been set up in this template document. Do not indent the first paragraph in each section.

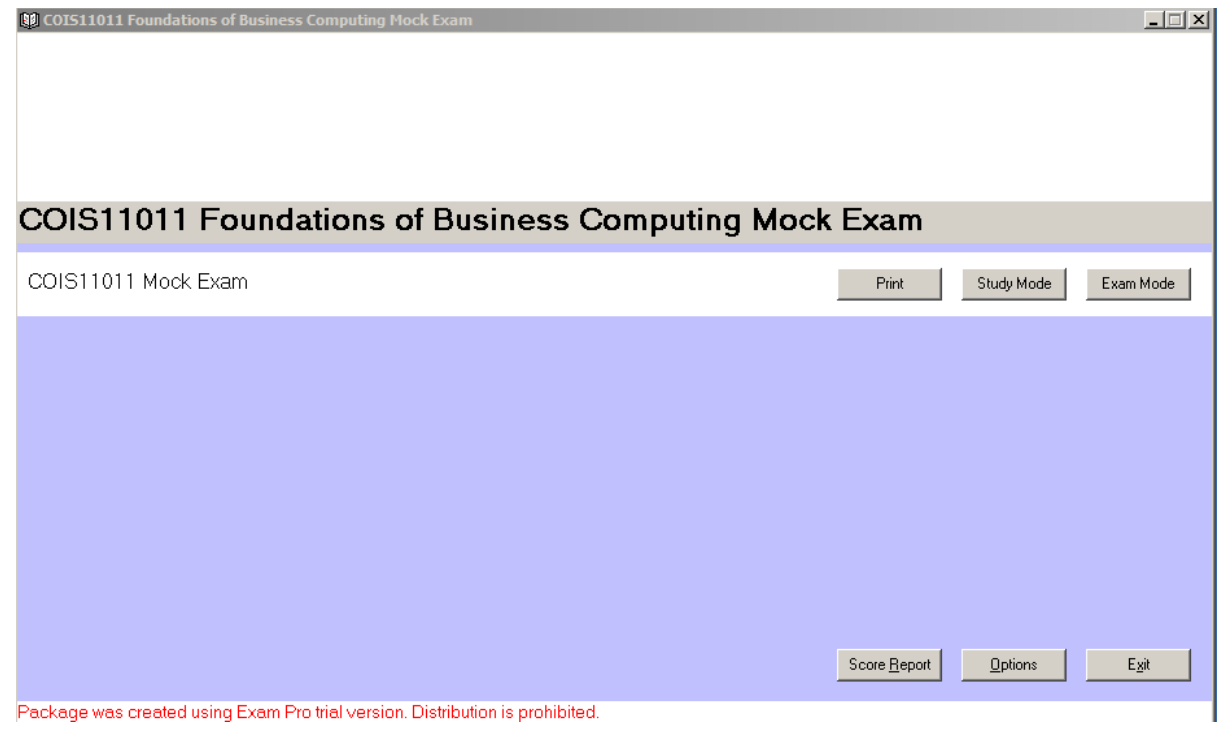

Figure 1: Screenshot of the e-exam for COIS11011 course.

The research involved the collection of qualitative data through focus groups interviews with students at CQUniversity. The university is home to five CQUniversity campuses scattered in regional Australia and four metropolitan campuses across three states. The research data were drawn from four focus groups interviews with 26 students aged between 18-45 randomly selected at CQUniversity enrolling at three courses: COIS13034 (an undergraduate information systems course), COIS20024 (a postgraduate course studied by accounting students) and STAT20028 (a postgraduate accounting course studied by mainly accounting students). These students were invited to participate in the study by email. Those who agreed to participate signed in an informed consent form and participated in a supervised e-exams consisting of short answer and essay questions. Shortly after completing the e-exams, the students participated in a one-hour long focus group interviews discussing their perceptions of the e-exams system. 
Exam Pro software was selected for the purpose of the study. The software has provision to administer multiple-choice questions (MCQs), True/False question types and essay type questions that can be administered remotely too. The exam questions were placed in the central server for security purposes and could be accessed by the students through an authentication process from multiple locations. Figure 1 shows the screenshot of the e-exam for COIS11011 course. Figure 2 below shows an instruction sheet and a question from the mock exam.

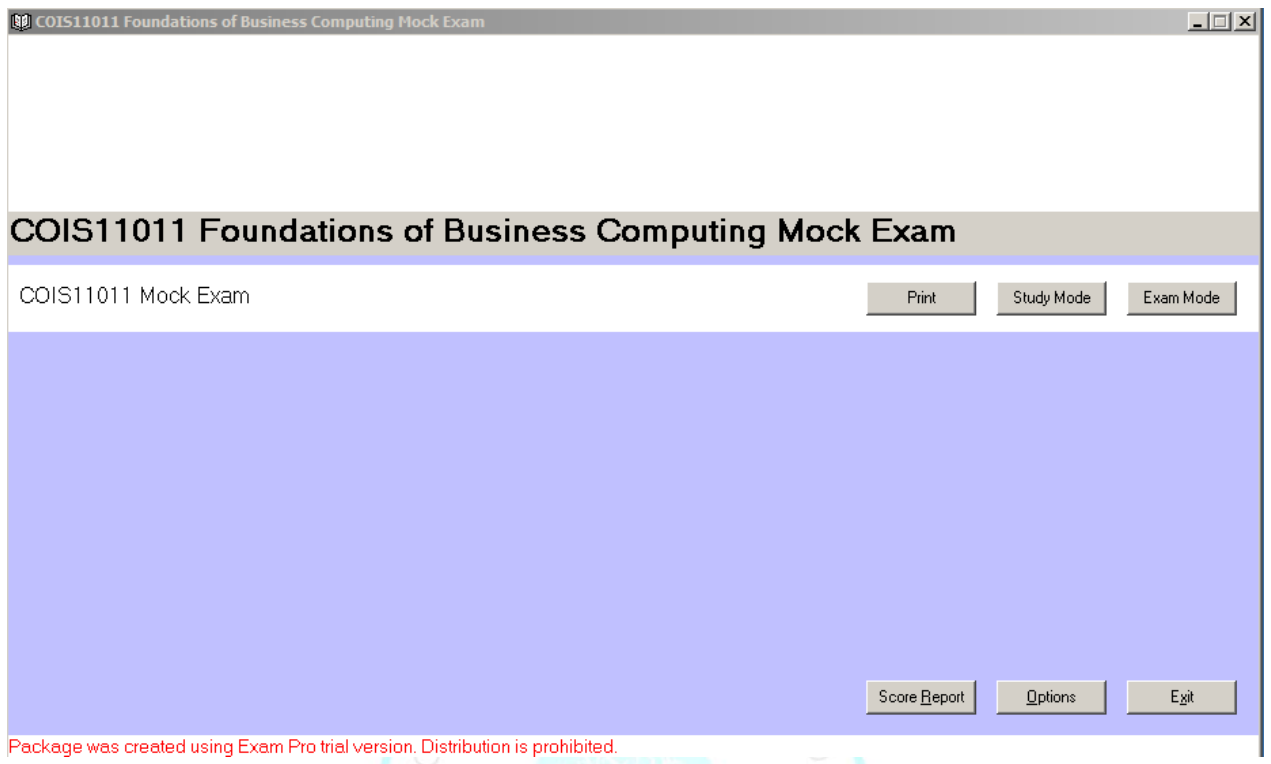

Figure 2: Instruction sheet and a question from the mock exam

The e-exam software has many functions including audio and video options. Figure 3 shows the e-exam with audio and video options.

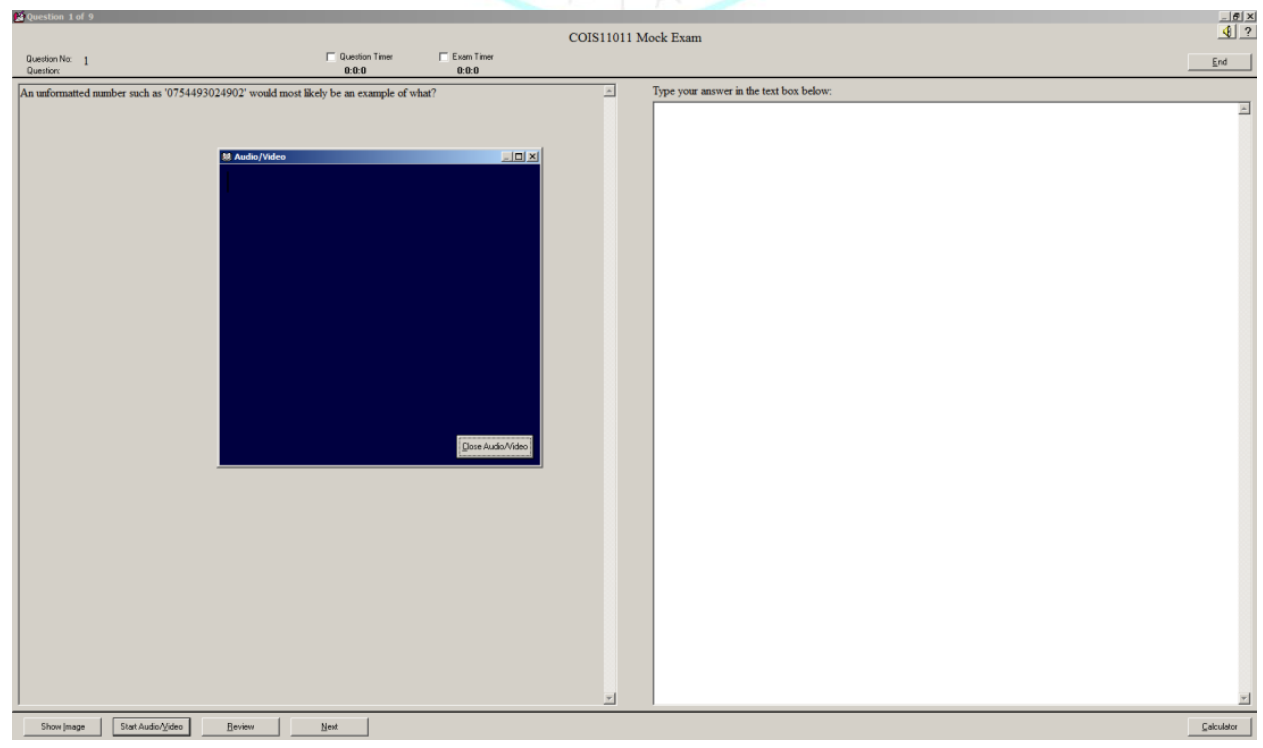

Figure 3: Audio and video options 
Figure 4 shows the complete mock exam report produced by the e-exam system after the exam has been completed by a student.

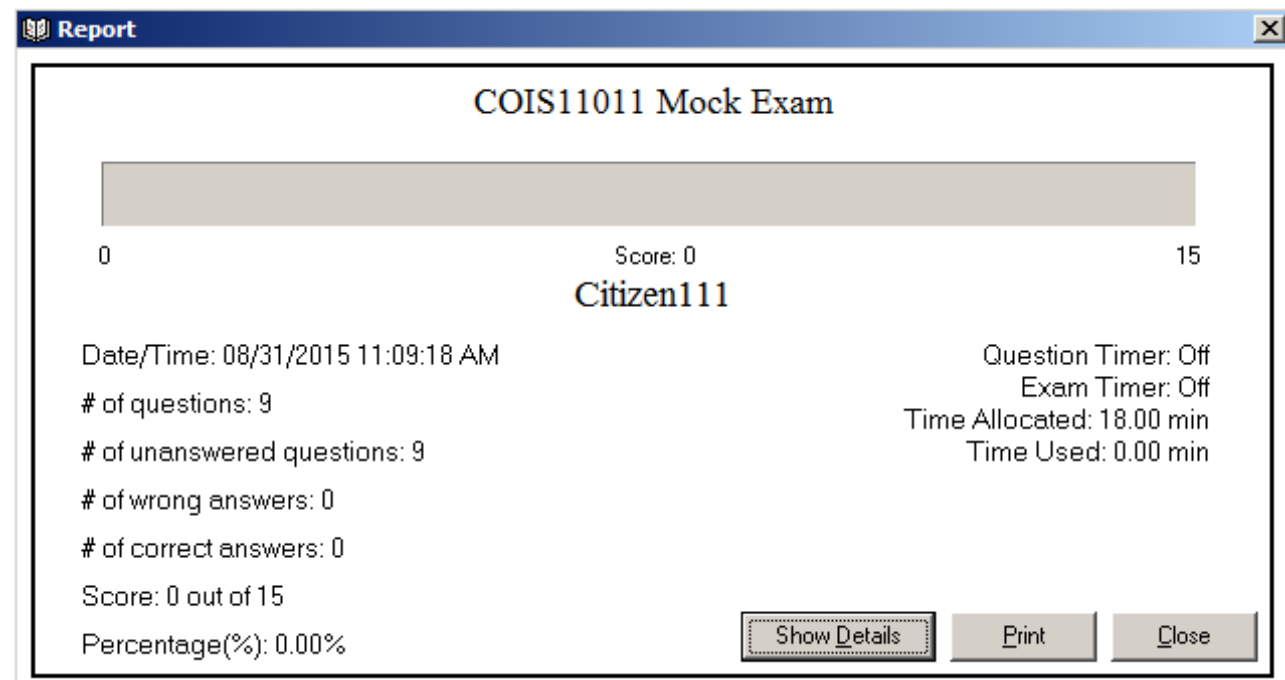

Figure 4: Complete mock exam report

\section{Findings}

This section discusses the students' views on e-exams software used in the study, the benefits and challenges associated with e-exams and future implementation of e-exams at their institution. The codes were used instead of students' names to protect their identities. Direct quotes from selected students were provided to enrich the discussion. Table 1 below provides a summary of students' responses to yes/no questions.

\section{1 The benefits of e-exams}

Keep line spacing at 1. Font type is Georgia. Font size is 11pt. Please do not alter the formatting and style layouts which have been set up in this template document. Do not indent the first paragraph in each section.

E-exams offered flexibilities. Students stated that they did not have to be physically present in the examination rooms as e-exams could be accessed from anywhere as the following students noted: 'we don't have to be physically present in the examination hall' (G4 R5), 'I found more advantages actually because with this offer we can now do our exams from the home when it is open book exams' (G4 R3). Students with sloppy handwritings benefited from e-exams. These students did not need to worry about their handwritings: 'it's clear everyone can read what you type (G1 R4) and 'the lecturer won't have a problem understanding what's written in the paper' (G2 R6). Students also mentioned losing marks due to their handwritings, which were difficult to read:

Yes I would prefer this typing exam, e-examination, because from my childhood I have got some remarks over my handwriting I lost so many marks because of handwritten examinations. (G2 R4)

When asked if the students preferred e-exams to paper-based exams, 16 students preferred the former. One of the reasons reported was that it was easier to type than write and if there were mistakes in the paperwork 'you had to use liquid paper or anything that made your exam paper 
look worse' (G2 R5). Students also mentioned that the adoption of e-exams would save raw materials and time:

One of the advantages is going to be save paper and it's a process where you are actually doing everything on here, so it's a computer it's all about saving raw material and stuff like that (G2 R5).

Rather than writing on the paper, it was pretty easy to type it and it wouldn't take as much time as it would take in a paper-based exam. So it was pretty good for me. It would save my time. So it was a really good experience ( $\left.\mathrm{G}_{1} \mathrm{R} 4\right)$.

Another benefit of e-exam was that it accelerates marking process

It's going to be easier to mark if it's going to be a variety of multiple choice and stuff. Let's say it's going to be a 10 question and then there would be 50 question of the test, and then the 10th question would be multiple choice, and then 20 question with short answers, and then these probably can be marked by machine, but then one of the essay question and short answer question can be marked by the actual teachers. So, that makes it a lot faster and easier (G2 R5).

Table 1: A summary of students' responses to yes/no questions

\begin{tabular}{|c|c|c|c|c|c|c|c|c|c|c|}
\hline \multirow[b]{2}{*}{ Questions } & \multicolumn{2}{|c|}{$\begin{array}{c}\text { Focus } \\
\text { Group 1 } \\
\text { (FG1), } \\
\text { n=6 }\end{array}$} & \multicolumn{2}{|c|}{$\begin{array}{c}\text { FocusGroup } \\
2 \text { (FG2), } \\
n=6\end{array}$} & \multicolumn{2}{|c|}{$\begin{array}{c}\text { Focus } \\
\text { Group 3 } \\
(\text { FG3),n=7 }\end{array}$} & \multicolumn{2}{|c|}{$\begin{array}{l}\text { FocusGroup } \\
4\left(\text { FG }_{4}\right), n=7\end{array}$} & \multicolumn{2}{|c|}{$\begin{array}{c}\text { All } \\
\text { studentsn }=\mathbf{2 6}\end{array}$} \\
\hline & Yes & No & Yes & No & Yes & No & Yes & No & Yes & No \\
\hline $\begin{array}{l}\text { Was it easy to } \log \text { on and begin the } \\
\text { exam? }\end{array}$ & 6 & o & 2 & 4 & 4 & 3 & 7 & o & 19 & 7 \\
\hline $\begin{array}{l}\text { Was navigating the e-exam } \\
\text { complicated? }\end{array}$ & 6 & o & 6 & o & 4 & 3 & 7 & o & 23 & 3 \\
\hline $\begin{array}{l}\text { Was the e-exam more stressful than } \\
\text { past paper-based exams? }\end{array}$ & 5 & 1 & 6 & o & 5 & 2 & 3 & 7 & 19 & 7 \\
\hline $\begin{array}{l}\text { Would you be willing to take e-exams in } \\
\text { other courses in the future? }\end{array}$ & 6 & o & 3 & 3 & 5 & 2 & 7 & o & 21 & 5 \\
\hline $\begin{array}{l}\text { Do you prefer a paper-based exam over } \\
\text { an e-exam? }\end{array}$ & 5 & 1 & 3 & 3 & 1 & 5 & 1 & 6 & 10 & 16 \\
\hline
\end{tabular}

A number of students said that, if well designed, e-exams could prevent students from cheating. The program allowed teachers to run a check on the system to see if two students had exactly the same answers.

The lecturer can use the e-exam to check if two students have cheated or like the answers are the same. If you are doing a paper-based like it's very difficult to figure out if the answers 
are the same, like you can't tell if the answer is the same exactly, but on e-exam you can just run a check and it will tell if the answers are similar or not (G2 R5).

\section{2 The Challenges of E-exams}

The challenges reported by the students included the unfamiliarity with the e-exams software, the restrictive nature of some software features, the malfunctioning of some tools, validity of the exams, the failure in Internet access and other personal factors. Several students said that they grew up in the culture that adopted paper-based exams, and therefore found e-exams unfamiliar. However, they believed that with more practice on the e-exams they became more familiar with the technology and became comfortable in using it.

Many students reported concerns related to the ineffectiveness of the navigation system. Almost all students (23) revealed that the navigation system was complicated. The layout lacked the Skip, Review and Forward buttons to enable students to go back and check previous questions, change their answers, check if their answers had been saved and see all questions and how they were structured at the same time. It also lacked important features to enable students to draw diagrams or figures. Students said they normally prioritised questions, which they thought were easy to answer. The current software was too rigid and did not have the tool to enable students to skip questions or went back to previous pages. Students, thus, could not approximate the amount of time spent on one question and move on to the next questions. One student expressed his/her concern:

I think I have done several computer tests, so it's going to be something like at least you can see every question whenever you want, and have a roll on if you start with question one and you can skip it, and then you can come back anytime you look and then you type, which is something I found out on the test is very inconvenient where you actually have to finish the whole thing just to come back to one question (G2 R5).

Some students expressed concern about losing time at the start of the exams and suggested a careful and proper log on. Once the students entered the wrong password at the start, they had to re-enter the password, which required longer time to log on. There was also a challenge of overwriting with other students' username and password as all students had the same login at the beginning. To log on and begin the e-exams involved many steps; the students suggested that it could be made simple by having a shortcut on the desktop. The specific time limit in eexams was distracting for some students:

Actually the navigation inside the exam interface between the questions was a bit confusing and time taking. That could be distracting especially having a specific time limit for different questions was a bit unnecessary because some people might spend less time for one part or more time for the other, but in general if we ignore the timing for each question the navigation inside the exam interface was a bit confusing and difficult basically (G3 R2).

Some students reported the malfunctioning of the software components. One student reported that the page he/she was writing collapsed after clicking the Review button. He/she had to retype the answer. Another student stated that when he/she pressed the Next question button, all the information about the last question was lost. Students suggested that the layout could include a Search Box or Dialogue Box Button and Index to allow them to jump directly to the questions they wanted to do. Colour Codes could be added in the navigation tree on the left hand side to indicate questions, which had not been answered. Other students suggested the following buttons such as 'Go', 'Next' or 'Back' were added in the navigation system. The students also suggested that the existing e-exams software should include a clear instruction explaining how to upload students' answers and where to send them. 
The timer button was particularly distracting and triggered stress. Unlike with paper-based exams, e-exams did not give students freedom to choose any question they wanted to answer first, which was very frustrating and increased students' anxiety level as the student below reported:

We are more under stress by doing an e-exam but if you are doing a paper-based exam we can take more time and think, and we can shuffle with the papers around and you know, we can think of the answers. But if you are doing the e-exam we have to skip around questions and find the question, so like it's a bit more frustrating ( $\left.\mathrm{G}_{2} \mathrm{R}_{5}\right)$.

Another challenge of e-exams reported was concerned with the validity of the exams. In the current e-exams the students had access to other resources on the screen. This gave them the opportunity to copy materials from online resources, which could pose a threat to the validity of the exams:

We can easily copy and paste. We shouldn't have the copy and paste button in that because many students including me, all we were doing was copying and pasting it from Google or Wikipedia which is a big disadvantage because most of the people, most of the invigilators they won't stand behind us and watch what we are doing right so it's better if we delete the copy and paste option (G4 R2).

A couple of students were concerned with power failure: 'like we are doing the exam and there is no power and everything shuts down so we are in trouble' (G1 R 5). Students felt disadvantaged from e-exams because of some personal factors. Students who were slow typists disadvantaged from e-exams:

For me the first disadvantage is that my typing is slow, so it's very difficult for me to complete the answer in that time. And in paperwork my writing is very good, and it's easy and bonus point for me, so I don't like this e-exam system (G2 R1).

Several students made a connection between writing and thinking. They described that that writing on paper helped them access their memory easier than typing on the computer and therefore, found e-exams challenging.

\section{3 The Prospects of E-exams}

Students positively welcomed the adoption of future e-exams. 21 out of 26 students were willing to take e-exams in other courses in the future:

'Yes, I would like to have this kind of e-exam instead of the paper-based if the structure is well designed' (G3 R2). Several students expressed their appreciations of the conduct of the current pilot project on e-exams as the following student stated 'in my opinion the project you have taken is very good so start this project as soon as possible' (G4 R6).

Students provided various feedbacks on the improvement of the existing e-exams. The feedback can be categorised into two broader themes: technical and institutional. On the technical level, major improvements to the navigation system were required. Useful features such as Skip, Review, Next buttons and a Save button should be added. Features indicating how and where to submit the exams and tools, which enabled students to draw diagrams, were found very useful and should be added. Students also suggested that the e-exams should not allow them to have access to other browsers to avoid cheating as the following students noted:

'while you sit in the exam then you can only access the e-exam based screen and you can only use the system' (G4 R1). 
At the institutional level students highlighted the importance of mock e-exams to give students the opportunity to familiarise themselves with the system and to understand how the software works:

I think it's better we do the mock exams first before preparing the real e-exams. It's better we do the mock exams so that we'll have an overview, we'll have an idea what to learn and what not to, how much time we are taking to answer a question, how much time we are focusing on one question, how much time we'll have the time balance also. It's better we do the mock exam first and later the real time because if we are attending the real exam directly, we will not have that much time to prepare. So it's good to have mock (G4 R2).

Students suggested that institutions or departments organised regular mock e-exams, for example, two weeks prior to the real e-exams. Institutions could also include in their website a link of samples of e-exams to give students the opportunity to practise in their free time, so students 'can grow the culture of e-exams' (G3 R2).

One key aspect, which should be considered in future adoption of e-exams, was the nature of the disciplines. According to students, e-exams worked well for particular courses. It was particularly suitable for IT courses or programming courses. Courses, which were more theoretical and had practical components, were less suitable with e-exams. This course requires students to draw graphs to illustrate the concepts. Students further noted that e-exams suited well with students with an IT background and believed that students from a non-IT background would find difficulties with e-exams:

I'm an IT student so I don't mind but for an accountancy student that is so rigid and not used to IT and all that, that student would find it really difficult. He could just stare at the questions for the whole exams because he doesn't know what to do (G1 R4).

\section{Discussion and Conclusion}

The study explored the students' understanding of current available e-exam systems, their perceived benefits and challenges and the prospects of e-exams. In general, the students positively welcomed the adoption of e-exams in their institution if the system was thoughtfully designed. Understanding students' attitudes toward e-exams were of paramount importance, as it would help teachers to better plan future implementation of the system. The student's attitude also provides a useful concept in predicting their learning outcomes (Cereijo, 2006; Mehra \& Omidian, 2011; Masrek, Aziz \& Johare, 2012).

Despite its potential, the implementation of e-exams posed many challenges, mostly associated with the unfamiliarity and the ineffectiveness of the e-exam software. Students made the point that the ineffectiveness of the software created stress. This confirmed previous study by Betlej (2013) that poorly designed e-exams software which put students under pressure and increased their stress levels. Even though there was no correlation between stress and test results (Leeson, 2009), the student in the study reported this concern. They stated that the pressure and the stress created by the ineffectiveness of the software affected their test results. This led to the importance creating a stress free environment and a first positive experience of e-exams to encourage students to adopt e-exams (Rout and Patnaik, 2011). Mock e-exams had been found to be effective in reducing the stress involved in e-exams. They gave students the opportunity to understand how the system worked thus became familiar with the system (Peat and Franklin, 2002).

It is timely that CQUniversity with its campuses in different locations in the region and interstates to implement e-exams. An examination conducted electronically help facilitate the 
examination process from conducting to marking the exams. The normal paper-based exams involve transferring exam papers from one campus to another within the region and interstates. This does not only take a vast amount of time and resources, but also runs the risk of exam papers being damaged or lost. The adoption of e-exams therefore reduces the complexity of the examination process conducted manually at multiple CQUniversity campuses.

There are two aspects should be considered if e-exams are to be implemented across all disciplines at CQUniversity. First, as reported by the students in the study, e-exams are not appropriate for all disciplines. Courses, which are theoretical-based or utilised a lot of handdrawn diagrams of were not suitable with e-exams (Hiller, 2004). Therefore, Hillier, (2014, p. 85) proposed that 'the implementation of e-exams would need to be tailored to the nature of the assessment undertaken in various discipline areas'. Second, and most importantly, the adoption of e-exams does not only involve the change in how examinations are conducted. It requires a change in the work pattern of academic staff. It is crucial that the university understands how academic staff across all disciplines perceives the adoption of e-exams. As Bhardwaj \& Singh (2011) noted changing people mindset, particularly those in their old age can be very difficult. A survey on teachers' attitude toward the system is worth conducting.

Successful implementation of e-exams requires a thoughtful selection of e-exams software and a collaborative effort of all staff in the university. Collaborative research among staff across different disciplines at the university provides useful insights into the adoption of e-exams. CQUniversity has just started adopting e-exams. Findings from this small-scale study could be used as a point of reference for future implementation of e-exams. Future research could be conducted with a larger sample and in a real exam environment to gain richer perspectives of the adoption of e-exams. 


\section{References}

i. Adebayo, O. \& Abdulhamid, S., 2010. "E-Exams System for Nigerian Universities with Emphasis on Security and Result Integrity". International Journal of the Computer, the Internet and Management, 18(2), pp. 471-472.

ii. Adegbija, M., Fakomogbon, M. \& Daramola, F., 2012. "The New Technologies and the Conduct Of EExaminations: A Case Study of National Open University of Nigeria. British Journal of Science, 3(1), pp. 59-66.

iii. Betlej, P., 2013. "E-examinations from student's perspective - the future of knowledge evaluation. Studia Ekonomiczne, Volume 153, pp. 9-22.

iv. Bhardwaj, M. \& Singh, A., 2011. "Automated Integrated University Examination System: A Security Concern”. Information Security Journal, 20(3), pp. 156-162.

v. Bodmann, S. \& Robinson, D., 2004. Speed and Performance Differences among Computer-Based and Paper-Pencil Tests. Journal of Educational Computing Research, 31(1), pp. 51-60.

vi. Dermo, J., 2009. "E-Assessment and the student learning experience: A survey of student perceptions of e-assessment. British Journal of Educational Technology, , 40(2), pp. 203-214.

vii. Dermo, J., 2009. "E-Assessment and the student learning experience: A survey of student perceptions of e-assessment”. British Journal of Educational Technology, 40(2), pp. 203-214.

viii. $\quad$ Fluck, A., Pullen, D. \& Harper, C., 2009. "Case study of a computer-based examination system". Australasian Journal of Educational Technology, 25(4), pp. 509-523.

ix. Fluck, A., Pullen, D. \& Harper, C., 2009. Case study of a computer-based examination system. Australasian Journal of Educational Technology, 25(4), pp. 509-523.

x. Hillier, M., 2014. "The very idea of e-Exams: student (pre) conceptions.. Australasian Society for Computers in Learning in Tertiary Education Conference, pp. 77-78.

xi. Hillier, M., 2014. The very idea of e-Exams: student (pre) conceptions. Australasian Society for Computers in Learning in Tertiary Education Conference, Ascilite.

xii. Hillier, M. \& Fluck, A., 2013. Arguing again for e-exams in high stakes examinations. Australian Society for Computers in Learning and Tertiary Education Conference, pp. 385-396.

xiii. Hillier, M. \& Fluck, A., 2013. Arguing again for e-exams in high stakes examinations. Ascilite, Australian Society for Computers in Learning and Tertiary Education Conference.

xiv. Jamila, M., Tariqb, R. \& Shami, P., 2012. Computer-based vs Paper-based Examination: Perceptions of University Teachers”. The Turkish Online Journal of Educational Technology, 11(4), pp. 371-381.

xv. Jamila, M., Tariqb, R. \& Shami, P., 2012. Computer-based vs Paper-based Examination: Perceptions of University Teachers”. The Turkish Online Journal of Educational Technology, 11(4), pp. 371-381.

xvi. Joseph, B., 2012. If We Build It They Will Come? The Technology Acceptance Model. In: Y. Dwivedi, M. Wade \& S. Schneberger, eds. Information Systems Theory: Explaining and Predicting Our Digital Society. Dordrecht: Springer, pp. 19-36.

xvii. Kuikka, M., Markus, K. \& Laakso, M., 2014. Challenges when introducing electronic exam. Research in Learning Technology, Volume 22, pp. 1-17.

Asia Pacific Institute of Advanced Research (APIAR)

10.25275/apjcectv4i1edu1 
xviii. Lyell, R. \& McNamara, S., 2000. Learning tool or potplant? Students' opinions of learning from a CAL program in a distance education context". Australian Journal of Educational Technology, 16(2), pp. 126-146.

xix. $\quad$ Masrek, M., Aziz, N. A. \& Johare, R., 2012. The Relationship between Internet attitude and Internet addition. Asian Journal of Information Technology, 11(4), pp. 125-130.

xx. Mehra, V. \& Omidian, F., 2011. Examining Students' Attitudes towards E-learning: A Case from India. Malaysian Journal of Educational Technology, 11(2), pp. 13-18.

xxi. Noubandegani, P., 2012. "Students' Perceptions of Computerized TOEFL Test". Language Testing in Asia, 2(2), p. 73 .

xxii. Osang, F., 2012. Electronic examination in Nigeria, Academic staff perspective-Case study: National Open University of Nigeria”. International Journal of Information and Education Technology, 2(4), pp. 304-307.

xxiii. $\quad$ Peat, M. \& Franklin, S., 2002. "Supporting student learning: The use of computer-based formative assessment modules. British journal of Educational Technology , 33(5), pp. 515-523.

xxiv. Rout, G. \& Patnaik, S., 2011. A case study on e-examination in Universities of Odisha. International Journal of Internet Computing , 1(2), pp. 12-20.

xxv. Ruyter, K. d. \& Scholl, N., 1998. Positioning Qualitative Research: Reflections from Theory and Practice. Qualitative Research: an International Journal, 1(1), pp. 7-14.

xxvi. Ryan, S., Scott, B., Freeman, F. \& Patel, D., 2000. The Virtual University, The Internet and Resource-Based Learning. London: Kogan Page.

xxvii. Shermis, M., Mzumara, H., Olson, J. \& Harrington, S., 2001. On-line grading of student essay: PEG goes on the world wide web. Assessment and Evaluation in Higher Education, 26(3), pp. 248-259.

xxviii. Thomas, P., Rice, B., Paine, C. \& Richard, M., 2002. Remote electronic examinations: student experiences. British Journal of Educational technology, 33(5), pp. 537-549. 